\title{
The Effects of Female Teacher Perceptions of Mathematics on the Quality of Teaching at The Basic School Level
}

\author{
Abubakar Yakubu \\ Mathematics / Information Communication and Technology Department \\ Bagabaga College of Education, Post Office Box 35 ER, Tamale, Ghana
}

\begin{abstract}
This study explored the influence of perceptions of Female Mathematics Teachers (FMTs) on their preparation, presentation and output of lessons delivered. Using a descriptive survey, 20 mixed primary schools were randomly selected for the study. Also, 11 Junior High Schools (JHSs) with Female Mathematics Teachers (FMTs) were purposively selected to participate in the study. All FMTs from the 31 basic schools selected were included in the study. The analysis of the data was based on percentage computations of responses from a questionnaire that was administered. The frequency of rejection or acceptance of items to a large extent represented the perceptions of FMTs in basic schools about their competence in lesson preparation and presentation. The findings show that FMTs at the primary and the JHS levels have very high confidence in themselves and felt they were equally as competent as their male colleagues. This fact notwithstanding, female teachers, teaching beyond the primary schools tend to avoid teaching mathematics. This is evident from the proportion of FMTs at the JHS and beyond in Ghana. The study recommends motivation, in-service training and scholarships for FMTs so as to equip more females to be able to teach Mathematics effectively at the basic level in Ghana.
\end{abstract}

Keywords: Competence, Female Mathematics Teachers (FMTs), In-service Training, Perception, Self-esteem DOI: $10.7176 / \mathrm{JEP} / 11-30-12$

Publication date:October $31^{\text {st }} 2020$

\section{Introduction}

Teachers in public primary schools in Ghana adopt multiple subject teaching, whereby a teacher teaches all the subjects taught in the class or teaches more than one subject. By this arrangement, public primary school teachers in Ghana teach mathematics as well. According to the data from Ghana Education Service (2018), the proportion of female to male trained teachers at the basic school in Ghana was $45.8 \%$ female and $54.2 \%$ male for primary school whilst at the JHS 30.3\% were females and 69.7\% males. The proportion for the Northern Region of the country is $26 \%$ female and $74 \%$ male for primary and $19.2 \%$ female and $81.8 \%$ male for JHS. This is an improvement in the gender proportions compared to the records for 2015/2016 academic year which was $46.6 \%$ female and $53.4 \%$ male for primary and $30.5 \%$ female whilst $69.5 \%$ are male for JHS. This improvement in the proportion of female teachers means a lot in mathematics teaching in Ghanaian primary schools since all these female primary school teachers teach numeracy, arithmetic or mathematics.

Thompson and Asare-Danso (2016) enumerates that the preoccupation of the constructivist teacher, as they term it, is to motivate young learners to indulge or engage in activities that would sustain their interest in concepts being learned. The teacher is thus expected to adopt attitudes and practices that would engage young learners in practical tasks. After pupils have successfully engaged in these tasks, teachers are expected to adopt appropriate assessment skills to probe the level of success of the task and concepts learned. Basic school mathematics teachers are expected to exhibit these skills in order to build the requisite mathematics foundation for pupils. These professional practices required of teachers and the expected output from pupils especially in mathematics is not what the records of BECE and WASSCE show, as year on year achievements relative to other BECE and WASSCE subjects are poorer for mathematics.

Several interventions have been implemented over the years by both the Ghanaian government and nongovernmental organisations to improve on achievement in mathematics and science at the basic level of education through practical or pupil-centred approaches. Some of these interventions by non-governmental organisations are; GES-JICA STM project (2002-2007), IBIS-ACE community teacher volunteer project (2012), UTTDBE programme (2005-2012), USAID e-learning project among others. All these projects were implemented in the Northern Region as well as other parts of the country.

The core areas of the mathematics curriculum at the basic level include numeracy, shape and space, algebra and data collection and handling. The GES Basic school syllabus for mathematics (2018) lists the core objectives of the JHS and primary schools' mathematics as follows;

The learner will:

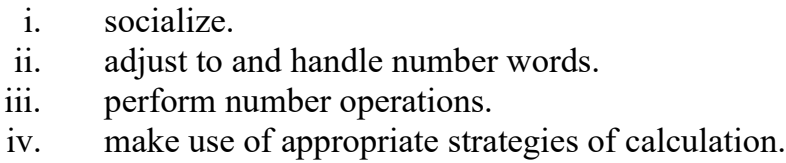


v. recognize and use patterns, relationships and sequence and make generalizations.

vi. recognize and use functions, formulae, equations and inequalities.

vii. use graphical representations of the equation and inequalities.

viii. identify/recognize the arbitrary/standard units of measure.

ix. use the arbitrary/appropriate unit to estimate and measure various quantities.

x. identify solid shapes in daily life.

xi. collect, process and interpret data.

A unique feature of the curriculum is to enable the learner to develop social values. Mathematics teachers have the task of implementing the curriculum, by adopting strategies that would ensure that learners do not only acquire content knowledge but also develop values that enables them to function effectively in society. As a college mathematics teacher, the relatively low entry behaviour of fresh students (Quality Assurance Office, Bagabaga college) seem to me as though teachers at the basic and secondary level put excessive attention on content mathematics to the neglect of other aspects of the mathematics curriculum. Large proportions of these fresh students have shortfalls in application of concepts learnt at pre-college mathematics.

Mathematics anxiety has been recognised as an impediment to students' achievement in Mathematics. Yet, fears and anxiety about Mathematics may have more widespread consequences than merely having an impact on the achievement of mathematics-anxious individuals themselves. If people who are anxious about mathematics are charged with teaching others mathematics-as is often the case for elementary school teachers-teacher's anxieties could have consequences for their student's mathematics achievement. (Sian, Beilock, Elizabeth, Ramirez, Susan, \& Levine, 2010). This assertion is buttressed by Fennema, (2000) who states that whether a boy or a girl likes or dislikes Mathematics, it may be the outcome of a complex process of social construction involving the teacher's or the parent's own gender stereotypes or both.

Perceptions of the majority of Ghanaians about mathematics has led to a stereotyping of the subject as a maledominated one. This is evident in the proportion of female Mathematics teachers at the JHS and Secondary school levels which are $25.3 \%$ for JHS and $19.6 \%$ for SHS (GES/EMIS 2007/2008). This is conceivably a reflection of the low proportion of females who pursue mathematics-related courses at the SHS level and mathematics or mathematics education at the tertiary level as well. These factors coupled with perceptions held by both male and female teachers might have a significant impact on the performance of female teachers, especially at the basic level. This study was therefore conducted to investigate the effect of female teachers' perception on their involvement as FMTs and the quality of their teaching.

\subsection{Purpose of the Study}

The purpose of this study was to investigate the self-esteem of mathematics teachers at the basic level and how it impacts on their competence.

For a clear direction of the study, in line with the purpose, the study sought answers to the following research questions

i. What attitudes do female teachers exhibit towards mathematics?

ii. What is the extent of female mathematics teacher preparation and lesson delivery?

iii. What challenges do female mathematics teachers face during teaching and learning of mathematics in Basic schools?

\subsection{Rationale for the Inclusion of Mathematics in Basic School Curriculum.}

In simple terms the curriculum encompasses all the learning experiences children go through in school under the guidance of the teacher. Though mathematics learning goes on both inside and outside the classroom the term mathematics curriculum may be misleading as it limits the true sense of the curriculum. Simply transmitting subject knowledge in a mathematics classroom is insufficient as a mathematics curriculum. 'Curriculum' is a term that has been given different interpretations by different scholars. According to Marsh (2009), the curriculum should not be used to accommodate social needs, instead, it should function as guidance for students to have further improvement. This description of the curriculum is rather narrow considering that the curriculum should offer learners the opportunity to develop academically as well as develop social and moral values.

Kelly (1999), clarifies that the curriculum is negatively viewed as a 'syllabus which may limit the planning of teachers to a consideration of the content or the body of knowledge they wish to transmit or a list of the subjects to be taught or both (p83). The department of Curriculum Management, Malta (2014), enumerates the rationale for the Basic school mathematics curriculum as 'The ability to develop and apply mathematical thinking in order to solve a range of problems in everyday situations. Through Mathematics, learners acquire a sound knowledge of numbers, measures and structures, basic operations and basic mathematical presentations, an understanding of mathematical terms and concepts, and an awareness of the questions to which mathematics can offer answers.

Both Kelly's (1999) and the Malta curriculum management (2014), demands of teachers of mathematics to plan beyond delivering content knowledge or a set of concepts or topics in the class. To be able to achieve this, 
teachers of mathematics should begin to see mathematics teaching as a responsibility to orientate his or her students to use the mathematics knowledge acquired to solve a range of problems encountered that would be encountered in daily life. 'The content of the Malta Basic school mathematics curriculum covers:

\subsection{Essential numeracy skills which support them in daily life.}

i. Key numeric competencies that include the understanding of concepts, principles, and applications

ii. Creative approaches in the four strands, namely, use of a number, measurement, space and shapes, and data handling.

iii. Logical thought and engagement with investigative processes that lead to solutions.

iv. Application of mathematical concepts on matters relating to financial decisions and planning. The curriculum emphasizes the need for children to experience mathematics as a rewarding and enjoyable experience. This can best be achieved by using a combination of different teaching styles and through differentiated teaching taking into consideration different learning styles.' This requirement for friendly and innovative learning strategies requires the mathematics teacher to acquire professional skills that would be enabling enough to achieve the objectives of the curriculum.

According to TIMMS and PIRL (2015), the goals of the primary mathematics curriculum are to:

i. Stimulate interest in the learning of mathematics

ii. Help students understand and acquire basic mathematical concepts and computational skills

iii. Help students develop creativity and the ability to think, communicate, and solve problems.

iv. Help students develop number and spatial sense and the ability to appreciate patterns and structures of number and shapes

v. Enhance student's lifelong learning abilities through basic mathematical knowledge

TIMMS and PIRL (2015) outlines that the curriculum covers five content areas at the primary level. These are Number, Shape and Space, Measurement, Data Handling and Algebra.

These two curricula are in tandem with the Ghana Education Service curricula which list the content of the Basic school mathematics as;

- Numbers and Investigation with numbers

- $\quad$ Shape and Space

- Measurement

- Collecting and Handling Data

- $\quad$ Problem Solving

- Investigation with numbers

Remillard (1999), cited in (Brown, Smith, and Stein 1996) observed that research on recent teacher development projects have revealed a need for teachers to have well designed curriculum guidance. Remillard adds that exactly how this guidance should look is not clear because we have limited knowledge of how teachers interact with and use curriculum materials, particularly those designed to promote curricular and pedagogical change. Evaluations of new materials tend to focus on student's experience and not the teacher's role in facilitating those experiences.

Stodolsky (1989) found that teachers consistently adhered to the topics in their textbooks, but departed from many accompanying teaching suggestions, particularly those not found on the student's page. Freeman and Porter (1989) also found that teachers use student exercises in texts considerably. This is a laidback approach to teaching which does not encourage innovative approaches by teachers and has a higher tendency of making mathematics lessons being delivered in a rote approach.

In Remillard's (1999), view merely identifying topics to add to the curriculum or tasks to pose to students does not determine how teachers enact them in the classroom.

\subsection{Perceptions of Female mathematics Teachers about Teaching Mathematics}

For most trainee teachers and fresh teachers, mathematics teaching remains more problematic than other subjects of the basic school curriculum especially at junior high school. It is considered to be more difficult and less enjoyable than Social Studies, Religious and Moral Education, Language and Art. Science and Technical Skills which are subjects largely related to mathematics are equally less attractive to female teachers.

In a study by Chionidou-Moskofoglou and Chatzivasiliadou-Lekka (2014) interviewees attributed the small number of women pursuing careers in Mathematics and Science to gender stereotypes, even though they admitted that both sexes want to perform well. Sava (2016), narrates that a female mathematics graduate reports that women are aware of the mathematics gender disparities and despite the encouragement, she remained scared throughout her undergraduate study. Male dominance and low self-esteem of FMTs definitely impacts on their output in mathematics lessons.

Gabriele (1995) implores that research, has shown that issues of gender differences in achievement in mathematics is not a biological factor, but a result of a mixture of social and cultural factors, societal expectations, 
personal beliefs systems and confidence levels. The self-confidence of both male and FMTs, students as well as pupils at the basic level, remain a major factor affecting mathematics teaching and participation of females. In spite of these factors a lot of improvement has been made, due to interventions implemented over the years. Gender mainstreaming, textbooks assigning equal roles to both sexes, role play and role models are some of the strategies improving mathematics gender equity in participation.

\subsection{The Impact of Anxieties of Female Mathematics Teachers on Pupils}

An article by Sian, Beilock, Elizabeth, Gerardo and Susan (2010) reports of anxieties among female mathematics teachers affecting the achievement of pupils in their class. The report further showed that female pupils are much affected since they are most likely to notice these female teacher anxieties compared to male pupils.

Mcpheat (2017), posits that self-awareness is being able to accurately assess how your emotions are affecting your performance, behaviour, and relationship and concludes that self-awareness is being able to discover your emotions. A teacher's emotions can affect his or her achievement of set targets and can as well make him or her a poor team player. Teachers who have low self-esteem might not be comfortable during lesson delivery and this can significantly affect performance.

The success in managing stress to lowest levels humanly possible and managing our time effectively rest in our ability to learn how to cope with everyday stressors which confront us every day and often without any prior warning and using creatively, the time we have at our disposal since there are no ways to increase it (Pipercoupolos, 2017. p13). As enumerated both teacher and pupil anxieties have an impact on learning time. Orientation and supporting FMTs to manage stress as well as removing situations like stereotyping would lead to an improvement in FMTs output. There is however limited information on a comparative study of differences in male-female teacher anxieties. Accordingly, differences in anxieties between male mathematics teachers and FMTs needs further probing.

Lyn, and David (2015), narrates that teachers of young children often report of anxieties, discomfort and difficulties in teaching mathematics. Most of these teachers also admitted to not seeing themselves as teachers of mathematics. Ginsburg and Ertel (2008) term this as 'identity issue'. They reported further that most teachers at the basic level admit they select teaching at this level because they do not want to teach mathematics at higher levels.

According to Lyn and David (2015), Perry (2011) in a survey, showed that female preservice teachers pursuing careers in elementary education have notably low confidence in learning mathematics. In the Ghanaian system where all basic school teachers teach mathematics, female teachers would most probably have difficulties in teaching mathematics during their probation period of teaching which span the duration of their first two years.

Jieun, Dong-eun and Robert (2017) on the contrarily reports of studies by Muralidharan and Shed (2016) and Rawal and Kingdon (2010) which found positive effects of female teachers on student achievements; using panel data from Andhra Pradesh, they found that female teachers are better at teaching girls than their male colleagues and no worse in teaching boys. It was further shown that for primary schools in rural Uttar Pradesh and Bihar, female teachers outperformed male teachers.

Dee (2007) finds from US data that female teachers perform worse in mathematics, but acknowledge that this could be due to the fact they were assigned to lower-performing classes. Similarly, Warwick and Jatoi (1994) found significant negative effects of females on grade 4 and 5 student's Mathematics achievements for Pakistan. Female mathematics teachers are most likely affected by self-awareness, citing the gender stereotyping that exists in mathematics teaching and the learning pursuit in Ghanaian schools.

\subsection{Perception of male Teachers about female Mathematics Teachers}

Perception is the mental pictures created which influence our construction of reality. In their study (Mediha \& Fatima, 2015) concluded that participants ascribe to attributes such as motherhood, sacrifice, fragility as feminine to female teachers whilst the features such as authority, power, leadership, discipline are accepted as masculine to male teachers. In their conclusion they considered their finding as an indicator that male teachers are not sufficiently aware of the multiple roles and responsibilities that their female counterparts have; maybe even describe them as 'inefficient and problematic workers' and 'elegant and fragile existences' (pp220). In a similar study by Celeste, Kasi, Penny, Susan, Nancy, Glennelle, \& Patricia (2000), female teachers alluded that, they were in a field dominated by men and lamented the differential treatment encountered by both female mathematics students and teachers in schools. The women spoke passionately of their roles as FMTs and considered it a unique position as women in mathematics. Celeste and her group recounted that women and men tend to differ in their approach to developing their mathematics lessons, for example, more women preferred group work and long-term assignments and mathematic projects whilst male teachers preferred traditional roles like direct delivery or short class activities. The direct link between self-concept and achievement may be fragile but the evidence that teacher attitude affects student performance is stronger.

Midgley, Feldlaufer, and Eccles (1989) visibly established that teacher effectiveness has a strong relationship 
with student's self-perceptions about abilities in mathematics. In effect, teacher's attitudes in mathematics may have an influence on how students perceive their own abilities to deal with mathematics. Midgley et.al. (1989) explains further that the association was found to be strongest for low achieving students who are taught by a teacher with low mathematics efficacy.

\section{Methodology}

The study employed descriptive research design and data collected fell largely in the qualitative research model. Descriptive research does not fit neatly into the definition of either quantitative or qualitative research methodologies, but instead it can utilize elements of both, often within the same study. This design allowed the researcher to gather the facts on the attitudes, perceptions, and self-esteem of female mathematics teachers in Tamale metropolis. The metropolis has a large teacher population at the basic level with a female population of 1299 which constitutes $47.3 \%$ of the total basic school teacher population (Metropolitan education Office, Tamale, 2018).

Primary data was collected using a questionnaire which was piloted in two primary schools and two junior high schools. This was to ensure the reliability of the items which was considered as a very important component of the study. One hundred and thirty Questionnaires were administered to 130 respondents with a response rate of $96.2 \%$.

Asamoah-Gyimah and Duodo (2007) explain that Descriptive design is usually in the form of statistics such as frequencies or percentages, averages and sometimes variability. Often graphs and other visual images of the results are used. Being a descriptive design, the data were analyzed using percentages computed from the frequencies of responses to each item. Statistical package for Social Sciences software (SPSS version 22) was used for analysis for analyzing the data.

\subsection{Sampling Technique}

The selection procedure was a blend of both probability and non-probability sampling techniques. The similarities in characteristics of the subjects allowed the adoption of Simple random sampling technique to select 20 Primary School whilst 11 Junior High Schools were purposively selected since they were the only JHS in the metropolis which had FMTs. All FMTs in the selected schools were incorporated into the sample. This process resulted in a sample size of 120 FMTs comprising 109 primary teachers and 11 JHS teachers.

\section{Results and Discussion}

Considering that the data collected were numerical in nature, data was analysed using SPSS software. Frequencies of the responses were converted to percentages for the analysis.

The academic qualifications of respondents ranged from diploma to a masters' degree in education. Out of the 120 respondents only 11 representing $9.2 \%$ were junior high school teachers. All the teachers teaching at the Junior high school had studied mathematics at the first-degree level as either a minor or a major subject. In an open-ended item, respondents were asked to indicate the challenges encountered by the female mathematics teachers. Challenges enumerated centred on unavailability of TLMs or resources in producing TLMs. Professional or academic competence was not mentioned as a challenge encountered. Female mathematics teachers at the basic level felt that it was prestigious to teach, in the midst of men, a subject that appears to be a male domain. Female mathematics teachers held a strong view that more in-service training and motivation in the form of recognition and scholarship were necessary.

Studies by Julia \& Lars (2017), show that professional development courses enable early childhood teachers to create a high quality learning environment to support children in their mathematical learning processes. They add that in general effective professional development takes time. 
Table 1: Perceptions of Female Teachers towards Mathematics Teaching

\begin{tabular}{lll}
\hline Statement & $\begin{array}{c}\text { Accept } \\
\text { \% }\end{array}$ & $\begin{array}{c}\text { Reject } \\
\text { \% }\end{array}$ \\
\hline Mathematics is a non-gender aligned Subject & 82.5 & 17.5 \\
Mathematics teaching at the Basic level is difficult & 23.4 & 76.6 \\
Use of TLMs helps pupils to learn effectively & 86.6 & 3.4 \\
Mathematics is better handled by male teachers & 16.6 & 83.4 \\
Sometimes it feels odd to introduce yourself as a female & 16.7 & 83.3 \\
mathematics teacher & & 45.0 \\
Gender stereotyping impacts negatively on the performance of & 55.0 & 87.5 \\
female Mathematics teachers. & 12.5 & 48.3 \\
Women are not physically fit to handle the numerous activities & 51.7 & 41.7 \\
involved in Mathematics teaching. & 58.3 & \\
Women and men differ in their approach to teaching Mathematics & \\
Teaching of Mathematics is a compulsion to me & & \\
\hline Source: Fingerk (2019)
\end{tabular}
Source: Fieldwork (2019)

The results in table 1 indicate a rejection by $82.5 \%$ of the general perception that mathematics is a masculine or gender aligned subject. The respondents were however, divided on whether there was a difference in the strategies/approach in teaching mathematics between male and female teachers. Whilst $51.7 \%$ agreed that there is a difference in approach, $48.3 \%$ disagreed with this statement. The difference in the response was $3.4 \%$. This assertion concurs with a study by Celeste et. al. (2000) which discovered that women differ in their approach to presenting lessons. According to them whilst women preferred group tasks like long term projects and assignments men preferred traditional roles like direct delivery or short class activities. Respondents also agreed that gender stereotyping impacts negatively on female mathematics teachers however a reasonably large proportion of $45 \%$ of them disagreed with this statement.

From the results, as many as $87.5 \%$ of the respondent felt that they were physically fit to handle activities involved in teaching mathematics. Further to this, a large proportion of $83.4 \%$ felt proud to introduce themselves as mathematics teachers. In open-ended item respondents indicated that they felt it was prestige to be a female mathematics teacher. The reason given was that the majority of pupils and teachers alike felt it was a male domain since it is dominated by male teachers. Notwithstanding the male dominance, female mathematics teachers maintained high levels of confidence as they hold the perception that they are equally as competent as their male counterparts in the realm of teaching mathematics. Chionidou-Moskofoglou and Chatzivasiliadou-Lekka (2014) attributed the small number of women pursuing careers in Mathematics and Science to gender stereotypes, even though they admitted that both sexes are eager to perform well. A considerably large proportion of 58.3\% indicated that the teaching of mathematics is a compulsion. Based on this, FMTs would most probably opt out of teaching mathematics if the opportunity is offered.

Table 2: Extent of Lesson Preparation and Delivery by Female Mathematics Teacher

\begin{tabular}{lcc}
\hline Statement & $\begin{array}{c}\text { Accept } \\
\mathbf{\%}\end{array}$ & $\begin{array}{c}\text { Reject } \\
\mathbf{\%}\end{array}$ \\
\hline With my rich experience I rarely use the syllabus in lesson planning & 44.1 & 55.9 \\
Most of the mathematics lessons delivered are examples from pupils & & 21.7 \\
textbooks and exercise books & 78.3 & 5.8 \\
Pupils have confidence in lessons I deliver in mathematics & 94.2 & 80.8 \\
I rely on my male counterparts for preparation of TLMs & 19.2 & 86.6 \\
I experience a feeling of extreme worry at the beginning of mathematics & 13.4 & 00.0 \\
Lesson & 00.0 & 64.1 \\
Household chores or responsibilities effects advance preparation for & 35.9 & 82.5 \\
mathematics lessons & 17.5 & 84.2 \\
It is not pleasant to discuss my mathematics lessons with male teachers & 15.8 & 60.8 \\
Scoring of pupils exercises poses a challenge to me & & \\
Enough teaching and learning resources exist in my school to support & 39.2 & \\
FMTs & & \\
\hline Source: Fidw & &
\end{tabular}

Source: Fieldwork (2019)

Responses on the first item in Table 2, reflect a divided opinion on the use of the syllabus in lesson preparation. Whilst $44.1 \%$ accepted that they seldom use the syllabus in lesson preparation $55.9 \%$ rejected the fact that they use the syllabus during lesson preparation. At school or during a college practice dubbed, 'on-campus', trainee 
teachers are encouraged to use the syllabus as a principal reference document for writing learning plans. A very large proportion of $94.2 \%$ stated that pupils have confidence in the lessons they deliver. This reflects adequate advance preparation for lesson delivery. Since issues of lesson delivery stress and anxiety can be reduced drastically through adequate preparation for lessons. An endorsement by $86.6 \%$ that they do not experience extreme worry further confirms that there is some efforts or at worst some consciousness for advance preparation.

From Table 2, as much as $78.3 \%$ agreed that lessons they deliver are largely examples and exercise from pupils' textbooks. Though this assertion in addition to the use of TLMs confirms the use of appropriate resource materials, it could also be an indication that female mathematics teachers simply present solved examples to pupils without introducing any innovative ideas or questions outside the pupils' textbooks in their lessons. This trend falls in line with the findings of Stodolsky's (1989) which shows that teachers consistently adhered to the topics in their textbooks, and departed from many accompanying teaching suggestions, particularly those not found on the student's page. Freeman and Porter (1989) also found that teachers use student exercises in texts considerably in class activities and exercise during lesson delivery.

Though a larger portion of respondents, $64.1 \%$ disagreed that household chores affect their preparation for lessons, a reasonable proportion of $35.9 \%$ accepted this fact

Table 3: Challenges FMTs Face during Teaching and Learning of Mathematics in Basic Schools

\begin{tabular}{lcc}
\hline Statement & Accept & Reject \\
& $\%$ & $\%$ \\
\hline
\end{tabular}

Male colleague teachers do not have confidence in my teaching of mathematics.

$22.5 \quad 77.5$

Most head teachers are reluctant to assign females to teach

Mathematics

The low proportion of female mathematics teachers at the JHS discourage me from teaching mathematics

Teachers, students and other stakeholders have the perception that mathematics is best taught by men negatively affect my teaching

Female teachers who do not teach mathematics view females teaching mathematics as odd.

TLM preparation and usage is a major challenge to me Another major challenge I encounter is choosing the appropriate teaching method for mathematics lessons Students negative attitude towards mathematics affects teaching and learning.

Insufficient in-service training for FMTs affect quality of mathematics lesson delivery.

There is low motivation from management which affects my teaching of mathematics. Source: Fieldwork (2019)

Negative perceptions and low confidence reposed in female teachers by their male colleagues could adversely affect FMT output. The results in table 3 show that the majority of respondents do not encounter the challenge which is supported by $77.5 \%$ who accepted that their male colleagues had confidence in their teaching. A large portion of $74.1 \%$ of respondents rejected the statement that the perceptions held by their male colleagues and pupils affect their output.

Sixty percent of respondents agreed that they do not encounter any difficulty in choosing appropriate teaching materials or strategies for their lesson whereas a reasonable proportion of $40 \%$ indicated that they encounter this challenge. This phenomenon could be solved through in-service training and motivation from management. From the results in the table, this was not the situation as a large representation of $81.7 \%$ accepted the assertion that insufficient motivation affects the quality of lesson delivery. Seventy-nine respondents representing $65.8 \%$ confirmed that there was low motivation from management. Low motivation which is a possible result of poor managerial practices can severely affect teacher morale.

\section{Conclusion and Recommendations}

The responses (Table 2) depicts that FMTs have high confidence in themselves in teaching the subject. This is true of FMTs at the primary level as the mathematics taught at this level does not demand high-level content knowledge. The low proportion of FMTs at JHS and beyond gives the wrong indication of their competence and amounts to 
gender stereotyping. Chionidou-Moskofoglou and Chatzivasiliadou-Lekka (2014) agrees with this view which indicates that despite this disparity females are equally as competent as their male colleagues in pursuing careers in mathematics. This is in line with similar assertions by Jieun et. al. (2017), From their findings, FMTs in basic schools are better at teaching girls and not less in teaching boys. This is because girls are inspired by FMTs as role models. FMTs also considered their roles as prestigious to find themselves in a field dominated by males coupled with a perception by most key players like headteachers who are reluctant to assign roles to females as mathematics teachers. Celeste et. al. (2000) corroborates this in a study where women testified that their roles as FMTs are vague.

Challenges encountered by FMTs could be mitigated through interventions like packaging in service-training to deepen their professional skills. Julia and Lars (2017) confirm that professional development course should enable early childhood teachers to create a high-quality learning environment to support children in their mathematical learning processes. Motivation for FMTs in the form of recognizing their competence, assigning mathematics oriented programmes and responsibilities to FMTs, material packages and scholarships must be implemented.

\section{REFERENCES}

Asamoah-Gyimah, K. \& Duodo, F. (2007). Introduction to Research Methods in Education. Institute for Educational Development and Extension. University of Education, Winneba.

Brown, C. A., Smith, S., \& Stein, M., K. (1996). Linking teacher professional development to enhanced classroom instruction. The annual meeting of the American Educational Research Association, New York.

Celeste, M., B., Kasi A., F., Penny P., G., Susan R., M., Nancy S. N., Glennelle P., \& Patricia S., (2000). Gender Consciousness and privilege. New York Falmer Press. Accessed August 2018 from https://www.amazon.com/GenderConsciousness-Privilege-Celeste-Brody/dp/0750709987

Chionidou-Moskofoglou, M. \& Chatziavasiliadou-Lekka K. (2014). Teacher's perceptions about gender differences In Greek Primary School Mathematics classrooms. Electronic Version. Retrieved August 2018. From http://www.researchgate.net/publication. Comparative Education Review 38 (3): 377-99 Edited by Pat Rogers and sasiele Kaisen London, The Jalmer Press.

Farmer, H., S. (1987). A multivariate model for explaining gender differences in career and achievement motivation. Educational Researcher, 16(2), 5-9. DOI: 10.3102/0013189X016002005

Fatima, B. \& Mediha, S. (2015). Investigation of Women Academicians' Perceptions Regarding "Being a Woman Academician”. Journal of Higher Education and Science, 5(1), 41-51. DOI: 10.5961/jhes.2015.108

Fennema, E. (2000). Gender and Mathematics: what is known and what do I wish was known. The Fifth Annual Forum of the National Institute for Science Education. Detroit: Michigan.

Gabriele, K. (1995). Equity in Mathematics Education. Influences of Feminism and Culture. London, UK. The Falmer Press.

Sari, M. \& Basarir, F. (2016). Analyzing teachers' perceptions of "female teacher" and "male teacher" within traditional gender roles. International Journal of Education and Research, 4(3), 205-224.

Julia, B., \& Lars E. (2017). Mathematics-related competence of early childhood teachers visiting a continuous professional development course: An intervention. Mathematics Teacher Education and Development. Retrieved from https://files.eric.ed.gov/fulltext/EJ1163878.pdf

Jieun L., Dong-eun, R., \& Robert, R. (2017). Teacher Gender, Student Gender, and Primary School Achievement: Evidence from Ten Francophone African Graduate School of International Studies, Korea University, Division of International Studies, Korea University

Kelly, A.V. (1999). The curriculum: theory and practice (4 ${ }^{\text {th }}$ ed.). London, UK: Paul Chapman Publishing Ltd.

Lyn, D., E. \& David, K. (2016). Handbook of International Research in Mathematics Education (3 ${ }^{\text {rd }}$ ed.). New York and London. Taylor \& Francis Group.

Marsh, C. J. (2009). Key concept for understanding curriculum. Retrieved March, 2019. http://qzabnsara.com/news/nf23256.pdf

Midgley, C., Feldlaufer, H., \& Eccles, J. S. (1989). Change in teacher efficacy and student self and task-related beliefs in mathematics during the transition junior high school. Retrieved March 2019 from https://psycnet.apa.org/record/1989-34691-001

Piperoupolos, G. P. (2017). Control your Stress and Manage your Time (1 $1^{\text {st }}$ ed.). https//bookboon.com/en/controlyour-stress-manage-your-time-ebook/download

Remillard, J. T. (1999). Curriculum Materials in Mathematics Education Reform: A Framework for Examining Teachers' Curriculum Development. University of Pennsylvania Philadelphia, PA. Retrieved March 2019 from, https://www.gse.upenn.edu/janiner/pdf/Remillard.CI.1999.pdf

Sava, N. H., (2016). Inventing the mathematics Gender, race and cultural understanding of mathematics. USA, State University of New York.

Sian, L., Beilock, I., Elizabeth, A. G., Gerardo, R. \& Susan, C. L., (2010). Female teachers' mathematics anxiety 
affects girl's mathematics achievement. The National Academy of Sciences of the United States of America. Retrieved February 2019 from https://www.researchgate.net/publication/41408684.

Stodolsky, S., (1989). Is teaching really by the book? In P.W. Jackson and S. Haroutunian-Gordon (Eds.), From Socrates to software: The teacher as text and the text as teacher. 159-184. Chicago: University of Chicago Press.

The Department of Curriculum Management Malta (2014). Mathematics syllabus; Year 1 to year 6. Retrieved August 2018. From https://curriculum.gov.mt/en/Curriculum/Year-1-to-6.

Thomas, S. D. (2007). Teachers and the Gender Gaps in Student Achievement. Journal of Human Resources. 42(3), 528-554. DOI: $10.3386 / \mathrm{w} 11660$.

Thompson, M. \& Asare-Danso, S. (2016). Effects of teachers' psychological orientation on kindergarten classroom instructional and assessment practices: a cognitivist/constructivist approach. Journal of Educational Development and Practice. 7(1), 111-133.

Warwick, D. P., \& Jatoi, H. (1994). Teacher gender and student achievement in Pakistan. Comp Education Rev, 